\title{
Aculope Onigienal \\ IgA, IgE E SUbClasses de IgG anti-CANDIDA albicans no SORO E LAVAdo VAGINAL DE PACIENTES COM CANDIDÍASE VULVOVAGINAL
}

\author{
Ricardo José Victal de Carvalho, Cristiane Martins Cunha, Deise Aparecida de Oliveira Silva, \\ Mônica Camargo Sopelete, Jane Eire Urzedo, Tomaz Aquino Moreira, \\ Paula de Souza Abreu Moraes, Ernesto Akio Taketomi" \\ Trabalho realizado no ambulatório de Alergia e Ginecologia da Unidade de Pesquisa em Alergia e \\ Imunologia Clínica do Hospital de Clínicas da Universidade Federal de Uberlândia e Divisão de Alergia \\ e Imunologia Clínica do Hospital MaterDei, Belo Horizonte, MG.
}

RESUMO - Овветivo. Determinar níveis de anticorpos IgA, IgE, IgG e subclasses (IgGI, lgG4) específicos a C. albicans no soro e lavado vaginal de mulheres com ou sem candidíase vulvovaginal para avaliar o papel destes anticorpos na imunopatogênese desta doença.

Ме́тоDos. Foram selecionadas 30 mulheres com sintomas clínicos de candidíase vulvovaginal (I5 com cultura de secreção vaginal positiva para C. albicans, II com cultura negativa e quatro com cultura positiva para Candida não-albicans) e 12 mulheres controles assintomáticas (nove com cultura negativa). Amostras de soro e lavado vaginal foram obtidas para a detecção de anticorpos anti-C. albicans por ELISA.

Resultados. Pacientes sintomáticas com cultura positiva apresentaram níveis de IgA específicas significativamente maiores no lavado vaginal e menores no soro do que aquelas com cultura negativa. Níveis séricos de IgE específica foram extremamente baixos em relação ao lavado vaginal. Altos níveis de IgG total específica foram encontrados no soro e lavado vaginal em ambos os grupos, independente da presença do fungo. Níveis de lgGI e lgG4 específicas foram significativamente maiores somente no lavado vaginal de mulheres sintomáticas e cultura positiva, com relação IgGI/lgG4 ligeiramente maior, indicando que a resposta de anticorpos $\lg \mathrm{GI}$ possa estar predominantemente envolvida na resolução da infecção fúngica.

Conclusöes. Nossos resultados indicam resposta acentuada de IgA, IgGI e IgG4 anti-C. albicans no lavado vaginal de mulheres sintomáticas com cultura positiva, sugerindo importante papel destes anticorpos na resposta imune local estimulada pela presença do fungo.

UnITERMos: Candidíase vulvovaginal. Candida albicans. IgA. IgE. IgG. lgGI. IgG4. Imunopatogênese.

\section{INTRODUÇÃO}

Fungos do gênero Candida são heterogêneos em suas características morfofuncionais, englobando aproximadamente 200 espécies. São habitantes comensais do trato gastrointestinal e genitourinário da espécie humana'. A maioria dos indivíduos desenvolve defesas imunológicas que impedem sua proliferaçãoe progressão para o desenvolvimento de candidíase localizada ou disseminada. Em algumas situações específicas onde ocorrem deficiências imunológicas, como por exemplo, o uso crônico de corticosteróides ou pacientes com AIDS, podem proliferar causando doenças de alta gravidade ${ }^{2}$.

* Correspondência:

Clínica da Universidade Federal de Uberlândia Unidade de Pesquisa em Alergia e Imunologia

Avenida Pará, 1720, Campus Umuarama

Bloco 4C, CEP 38400-902, Uberlândia, MG taketomi@ufu.br
Candidíase vulvovaginal é uma entidade ginecológica freqüente, estimando-se que a maioria das mulheres $(75 \%)$ apresentará ao menos um episódio da infecção no decorrer de sua vida e $40 \%$ terão um segundo episó$\mathrm{dio}^{3}$. Algumas mulheres (3\%-5\%) apresentarão candidíase vulvovaginal recorrente, quese caracteriza pela apresentação de pelo menos quatro episódios em um ano ${ }^{4}$. $O$ uso de anticoncepcionais orais, antibióticos e as várias formas de imunodeficiência podem estar envolvidos no desencadeamento destes episódios de infecção de repetição².

Do ponto de vista imunológico, as mucosas do trato respiratório superior e genital inferior são muito semelhantes, sugerindo a ocorrência de mecanismos similares de reação de hipersensibilidade 5 . Recentemente foram descritos quadros de processos alérgicos concomitantes à candidíase vulvovaginal, principalmente a rinite alérgica ${ }^{6}$. Witkins etal. ${ }^{7}$ identificou anticorpos lgE específicos a
C. albicans no lavado vaginal de mulheres com vaginite recorrente. Moraes ${ }^{6}$ encontrou maior incidência de rinite alérgica em mulheres portadoras de candidíase vulvovaginal de repetição comparado ao grupo controle.

Diferentes classes de anticorpos anti-C. albicans ( $\operatorname{lgM}, \lg G, \lg A$ ) foram determinadas tanto no soro como em secreções cervicovaginais de mulheres com ou sem candidíase vulvovaginal, com a finalidade de investigar o seu papel na imunopatogênese da doença $^{8,9,10,11}$. Entretanto, o papel das subclasses de anticorpos lgG ainda não tem sido investigado em candidíase vulvovaginal como ocorre em doenças alérgicas tais como asma, rinite alérgica e eczema atópico ${ }^{12,13}$.

$O$ objetivo deste estudo foi determinar níveis de anticorpos $\lg \mathrm{A}$, $\lg E$, lgG e suas subclasses (lgG I elgG4) no soro e lavado vaginal de mulheres com ou sem candidíase vulvovaginal para avaliar o papel destes anticorpos nos mecanismos imunopatológicos desta doença. 


\section{Métodos}

Foram selecionadas 30 mulheres com sintomas de candidíase vulvovaginal (prurido vulvar eardência) e sinais clínicos de secreção ou hiperemia vaginal (grupol) na faixa etária de 18 a 36 anos, atendidas no Ambulatório de Alergia e Ginecologia da Unidade de Pesquisa em Alergia e Imunologia Clínica da Universidade Federal de Uberlândia (UFU), no período de março a outubro de 200I. Doze mulheres assintomáticas, com a mesma faixa etária (grupo II) foram selecionadas dentre as mulheres que estavam realizando exames colpocitológicos de rotina para prevenção do câncer de colo uterino. Este estudo recebeu aprovação do Comitê de Ética em Pesquisa da UFU envolvendo seres humanos e um termo de consentimento foi obtido de todas as participantes do estudo.

O diagnóstico definitivo de candidíase vulvovaginal foi realizado por meio de história e exame clínico e presença de Candida albicans em cultura. Swabs de secreção vaginal foram obtidos e encaminhados ao Laboratório Central de Análises Clínicas da UFU para análise por pesquisa direta e cultura em meio de ÁgarSabouraud. Para a diferenciação de espécies foi utilizado o meio CHROM-Ágar.

Amostras de lavado vaginal foram obtidas por meio da instilação de $5 \mathrm{ml}$ de soro fisiológico estéril no fundo de saco vaginal e subsequente aspiração com a mesma seringa. As amostras foram imediatamente enviadas ao Laboratório de Imunologia da UFU, centrifugadas a $3645 \mathrm{~g}(4500 \mathrm{rpm})$ a $4^{\circ} \mathrm{C}$ por $\mathrm{I} 5 \mathrm{~min}$ e os sobrenadantes obtidos foram armazenados a $-20^{\circ} \mathrm{C}$ até a realização dos ensaios para a detecção de anticorpos específicos a C. albicans.

Amostras de sangue foram obtidas por meio de punção venosa concomitantemente às amostras de lavado vaginal. Após centrifugação a I I 25g (2500 rpm) por 10 minutos à temperatura ambiente, os soros obtidos foram aliquotados e armazenados a $-20^{\circ} \mathrm{C}$ até a realização dos testes sorológicos.

Ensaios imunoenzimáticos (ELISA) foram realizados para a determinação dos níveis de anticorpos (IgA, IgE, $\lg G, \lg G \mid$ e lgG4) específicos a C. albicans nas amostras de soro e lavado vaginal de pacientes e controles, segundo Silva et al. ${ }^{15}$, com modificações. Em resumo, microplacas de alta afinidade foram sensibilizadas com extrato antigênico de C. albicans (Bayer Corporation, USA) a I:20 em tampão carbonato $0,06 \mathrm{M}, \mathrm{pH} 9,6$, durante $18 \mathrm{~h}$ a $4^{\circ} \mathrm{C}$. Placas foram lavadas com PBS (salina tamponada com fosfatos) contendo $0,05 \%$ de Tween 20 (PBS-T) e bloqueadas com PBS-T acrescida de BSA (soroalbumina bovina) a $1 \%$ (PBS-T-BSA) por I h a temperatura ambiente (TA). Etapas subseqüentes foram realizadas utilizando PBS-T-BSA como diluente e lavagens com PBS-T foram feitas entre as etapas da reação. As placas foram incubadas com amostras de soro a l:2 (IgE), l:5 ( $\lg G 4)$, I: I0 (IgA, IgG, IgGI) e lavado vaginal não diluído (lgE) e I:2 (IgA, IgG, IgG I, lgG4), em duplicata, durante I h (IgA, IgG e subclasses) ou $2 \mathrm{hs}(\mathrm{IgE})$ a $37^{\circ} \mathrm{C}$. Em paralelo, como controle negativo dos soros e amostras de lavado vaginal, somente diluente (PBS-T-BSA) foi utilizado para todas as classes de anticorpos. Subseqüentemente, anticorpos secundários respectivos foram adicionados como anti-IgE humana biotinilada ( $I: 250$; Kirkegaard \& Perry Laboratories, USA), anti-IgA e anti-lgG humanas marcadas com peroxidase ( $1: 1000$; Sigma Chemical Co., USA) e anticorpos monoclonais anti-lgGI (I:500; Sigma) e anti-lgG4 humanas (I:200; Sigma) por I h a $37^{\circ} \mathrm{C}$. Finalmente, conjugado estreptavidina-peroxidase ( $1: 250$; Sigma) foi adicionado nas placas com anticorpo secundário biotinilado e anti-lgG de camundongoperoxidase (I:500; Sigma) para os anticorpos monoclonais, incubando-se por 30 min a TA. A reação foi desenvolvida pela adição de substrato enzimático (ABTS $0,01 \mathrm{Me} \mathrm{H}_{2} \mathrm{O}_{2}$ a $0,03 \%$ ) e os valores de DO (densidade óptica) foram determinados em leitor de ELISA (Titertek Multiskan Plus, Flow Laboratories, USA) a $405 \mathrm{~nm}$. Os resultados foram expressos em unidades de reatividade ELISA (UE) e calculados pela fórmula UE = DO líquida (DO da amostra $D O$ do controle negativo) $X$ fator de diluição, como proposto por Yi et al ${ }^{16}$.

A análise estatística consistiu de determinações de média aritmética e desvio padrão dos níveis de anticorpos (UE) específicos a $C$. albicans e as diferenças entre as médias foram analisadas pelo teste $t$ de Student. Diferenças foram consideradas como estatisticamente significativas para $\mathrm{p}<0,05$.

\section{Resultados}

Entre as 30 mulheres com sintomas clínicos de candidíase vulvovaginal, I5 (50\%) apresentaram positividade para $C$. albicans em cultura de secreção vaginal, II (36,7\%) foram negativas e quatro $(13,3 \%)$ foram positivas para outras espécies de Candida. Entre as 12 mulheres controles, nove $(75 \%)$ apresentaram cultura negativa enquanto três $(25 \%)$ foram positivas para C. albicans. Devido ao reduzido número de mulheres controles com cultura positiva, este subgrupo foi excluído para análises estatísticas.

Respostas de anticorpos lgA e lgE anti-C. albicans em amostras de soro e lavado vaginal de pacientes (grupo I) e controles (grupo II) com cultura vaginal positiva (cultura + ) ou negativa (cultura -) estão demonstradas na Figura I. Mulheres com sintomas clínicos de candidíase vulvovaginal (grupo I) com cultura positiva apresentaram níveis médios de lgA anti-C. albicans em amostras de soro significativamente menores do que aquelas com cultura negativa $(5,83$ versus $7,55 \cup E ; p=0,0453)$. Por outro lado, em amostras de lavado vaginal, níveis de lgA específica foram significativamente maiores em pacientes com cultura positiva $(I, \mid 9$ versus $0,5 I \cup E ; p=0,0422)$. Em relação aos anticorpos $\lg E$ anti-C. albicans, níveis séricos de lgE específica foram extremamente baixos em relação aos valores encontrados no lavado vaginal, embora diferenças significativas foram encontradas apenas em amostras de soro do grupo I com cultura positiva $(0,19$ versus $0,16 \cup E ; p=0,0121$ ).

A resposta de anticorpos IgG total e subclasses lgGI, lgG4 anti-C.albicans está ilustrada na Figura 2. Níveis de lgG total específica em amostras de soro e lavado vaginal não apresentaram diferenças significativas tanto em pacientes como em mulheres controles, independentemente dos resultados de cultura vaginal. Similarmente, níveis séricos de lgG I e lgG4 específicas não mostraram diferenças significativas entre os grupos e respectivos subgrupos. Entretanto, em amostras de lavado vaginal, os níveis de lgG I e lgG4-anti-C. albicans foram significativamente maiores em mulheres com sintomas clínicos e cultura vaginal positiva do que naquelas com cultura negativa $(I, 65$ versus 0,20 $\mathrm{UE} ; p=0,0016$ e 0,60 versus 0,20 UE; $p=$ 0,0082 , respectivamente). 
Figura I - Níveis de anticorpos IgA e IgE anti-C. albicans, expressos em Unidades de Reatividade ELISA, em amostras de soro e lavado vaginal de 26 mulheres com sintomas clínicos de candidíase vulvovaginal e de 12 mulheres sem sintomas clínicos (controles), de acordo com resultado da cultura de secreção vaginal a C. albicans. As barras horizontais indicam as médias aritméticas (m.a.) para cada grupo
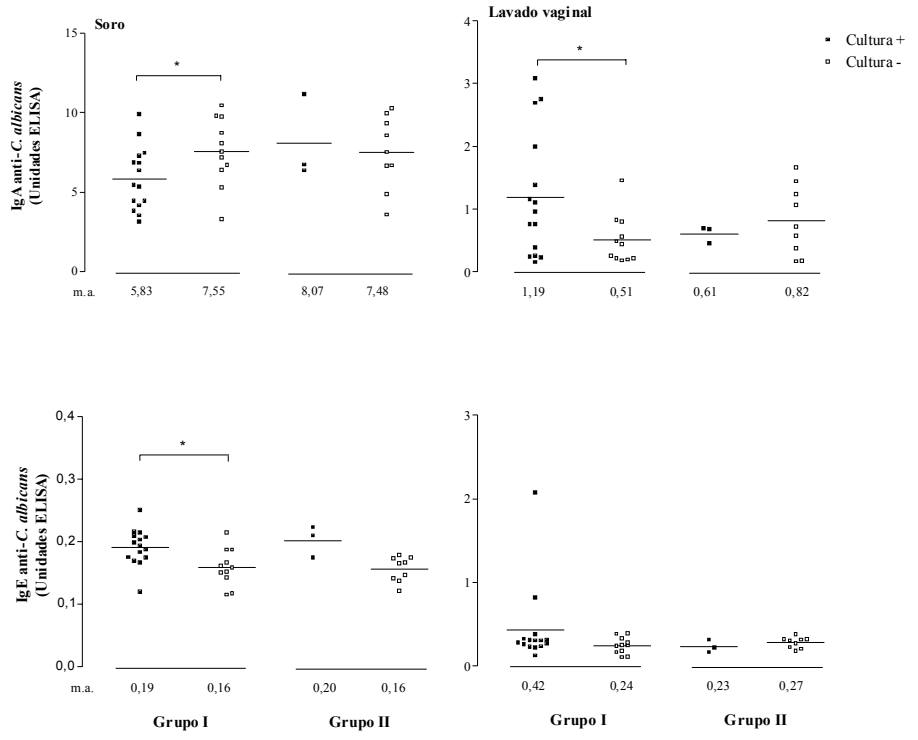

Figura 2 - Níveis de anticorpos IgG e suas sub-classes IgGI e lgG4 anti-C. albicans, expressos em Unidades de Reatividade ELISA, em amostras de soro e lavado vaginal de 26 mulheres com sintomas clínicos de candidíase vulvovaginal e de 12 mulheres sem sintomas clínicos (controles) de acordo com resultado da cultura de secreção vaginal a $C$. albicans. As barras horizontais indicam as médias aritméticas (m.a.) para cada grupo.

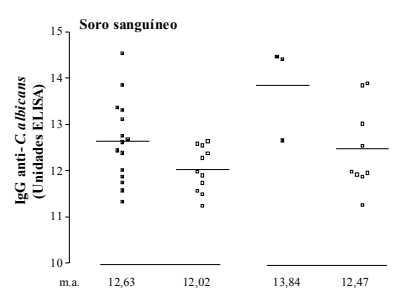

${ }_{0}^{4}$
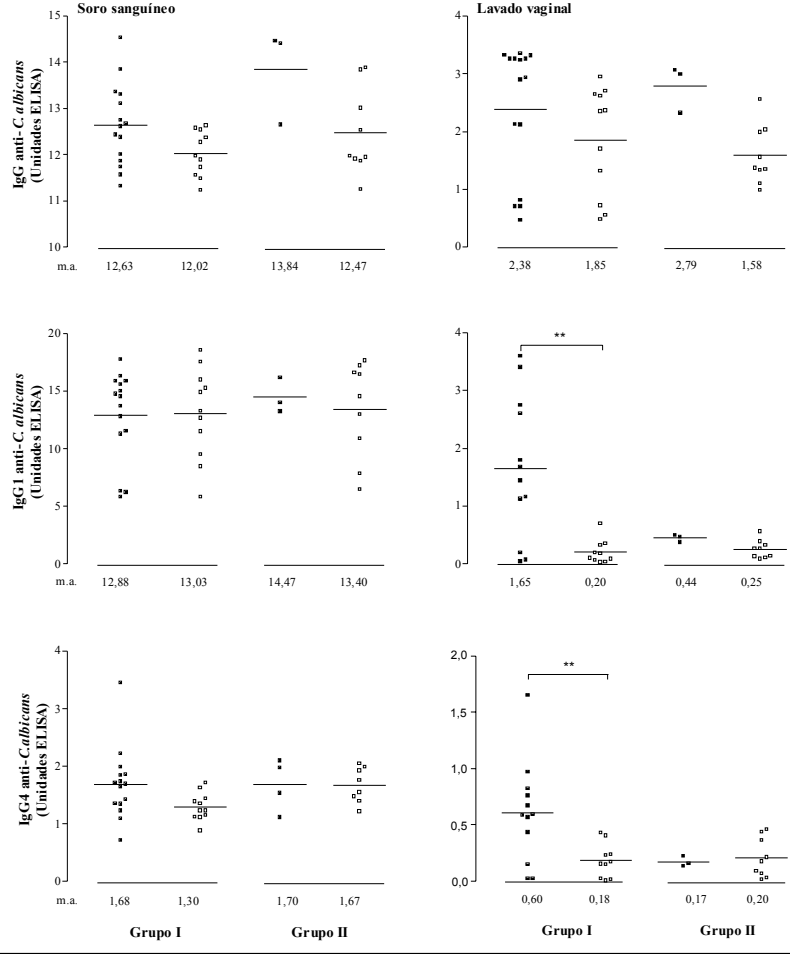

A Figura 3 demonstra a relação $\lg G \mid /$ lgG4 especíica a $C$. albicans tanto em amostras de soro como no lavado vaginal de ambos os grupos. Nenhuma diferença estatisticamente significativa foi observada para as amostras de soro, porém em amostras de lavado vaginal, observou-se uma tendência (no limite de significância) para relação $\operatorname{lgGl} / \operatorname{lgG} 4$ aumentada no grupo de pacientes com sintomas clínicos e cultura positiva em comparação àquelas com cultura negativa $(2,90$ versus I, $65 \mathrm{UE} ; \mathrm{p}=0,0558)$.

\section{Discussão}

Dados da literatura têm mostrado que 85\%-90\% dos fungos isolados de secreção vaginal são identificados como Candida albicans. Entretanto, porcentagens crescentes de infecções por outras espécies de Candida têm sido relatadas. Muitas mulheres são portadoras assintomáticas de C. albicans quando em baixo número. Estas observações são compatíveis com o conceito de que $C$. albicans é considerada como comensal ou patógeno vaginal, indicando que as alterações no ambiente vaginal do hospedeiro são necessárias para induzir os seus efeitos patológicos ou estar associado com sintomas ${ }^{16}$.

Entre os fatores predisponentes à candidíase vulvovaginal, destacam-se as condições que induzem imunodepressão, tais como a gravidez, o diabetes, o uso de corticosteróides e AIDS, ou o uso de antibióticos que alteram a flora vaginal normal. No presente estudo, tais fatores não foram avaliados, uma vez que foram considerados como critérios de exclusão na formação dos grupos. Desta forma, para análises comparativas foram avaliadas pacientes sintomáticas (grupo I) com cultura de secreção vaginal positiva ou negativa para $C$. albicans e assintomáticas (grupo II) com cultura negativa.

A resposta vaginal de hipersensibilidade mediada por IgE a C. albicans pode ser um fator contribuinte à vaginite recorrente em um determinado grupo de mulheres susceptíveis ${ }^{7}$. A liberação de histamina e prostaglandina E2 induz a uma resposta inflamatória e imunossupressão localizada, que favorece a proliferação de $C$. albicans e outros microrganismos oportunistas. Assim, aqueles autores demonstraram que cerca de $18 \%$ dos pacientes com candidíase vulvovaginal recorrente apresenta- 
Figura 3 - Relação dos níveis de IgGI/lgG4 anti-C. albicans, em amostras de soro e lavado vaginal de 26 mulheres com sintomas clínicos de candidíase vulvovaginal e de 12 mulheres sem sintomas clínicos (controles), de acordo com resultado da cultura de secreção vaginal a $C$. albicans. m.a.= média aritmética.
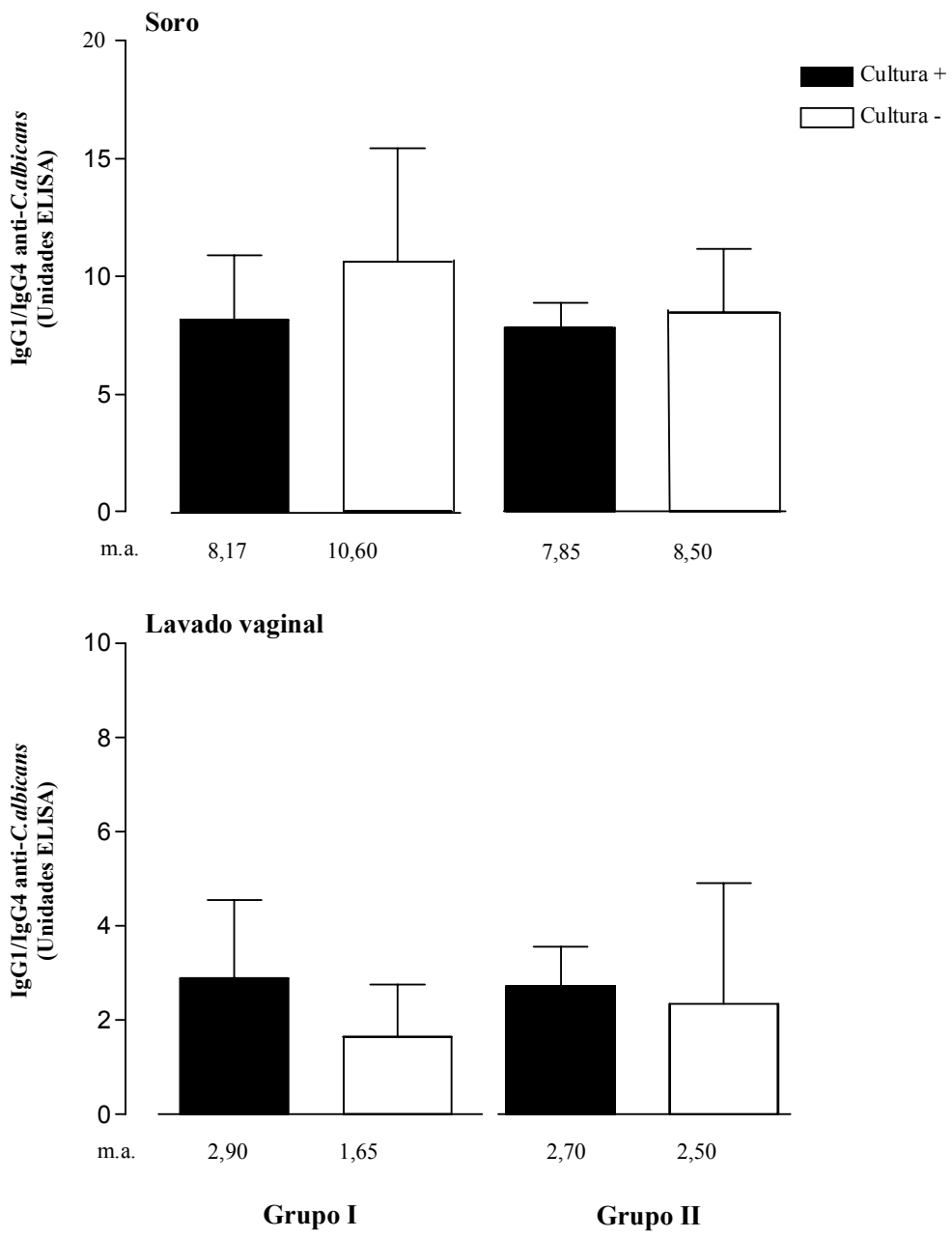

ram lgE no lavado vaginal e apenas $6 \%$ apresentaram lgE no soro, sugerindo uma resposta de hipersensibilidade imediata localizada. No presente trabalho, os níveis de anticorpos $\lg \mathrm{E}$ no soro, mas não no lavado vaginal, foram discretamente maiores apenas no grupo I com cultura positiva. Estes resultados divergentes podem ser devido ao fato de que o nosso principal grupo de estudo compreendeu pacientes com sintomas clínicos de candidíase, mas não de forma recorrente.

Nossos resultados mostraram diferente resposta anticórpica de $\lg A$ anti-C. albicans dependendo do compartimento imunológico (soro e lavado vaginal) analisado em pacientes com sintomas clínicos de candidíase, indicando uma resposta local mais acentuada nas pacientes com cultura positiva, enquanto a resposta sistêmica está mais acentuada nas pacientes com cultura negativa. Isto poderia refletir que a síntese de anticorpos IgA associada às mucosas estaria sendo estimulada na vigência da infecção ativa, ao passo que a resposta sistêmica (presença de IgA no soro) poderia refletir uma exposição anterior. Por outro lado, altos níveis de anticorpos IgG total anti-C. albicans foram encontrados tanto no soro como no lavado vaginal em ambos os grupos, independente da presença do fungo, indicando a exposição constante ao agente, refletindo na existência de memória imunológica. Estes dados são concordantes com os de Burges et al. ${ }^{8}$, que encontraram lgG como classe de anticorpo predominante em pacientes com candidíase vulvovaginal. Entretanto, estudos anteriores não têm encontrado diferença significativa nos níveis de IgA específica como os de Bohler et al. ${ }^{17}$ e Gough et al. ${ }^{9}$ ou $\lg G$ específica como os de Gough et al. ${ }^{9}$ no soro e/ ou secreções vaginais de pacientes com ou sem candidíase.

Enquanto a resposta sistêmica e local de IgG total específica a C. albicans não apresentou diferença significativa entre os grupos, 0 perfil de resposta das subclassses de lgG ( $\lg$ I e lgG4) específica mostrou que ambas estão aumentadas no lavado vaginal de pacientes sintomáticas com cultura positiva quando comparadas com aquelas sintomáticas com cultura negativa, indicando importante papel destas subclasses na resposta imune local estimulada pela presença do fungo, ao contrário do que foi observado na resposta sistêmica destas subclasses. Analisando a relação lgGI/lgG4 específicas a C. albicans, pôde-se notar nítida tendência de aumento dessa relação no grupo de mulheres com sintomas clínicos e cultura positiva comparativamente àquelas com cultura negativa, sugerindo que a resposta de lgG I possa estar predominantemente envolvida para a resolução da infecção fúngica.

Esta investigação representa um dos primeiros estudos relacionados às subclasses de IgG específicas a C. albicans e estudos futuros deverão ser realizados para esclarecer o papel protetor ou imunopatológico das subclasses de lgG em mulheres portadoras de candidíase vulvovaginal.

\section{Conclusão}

Nossos resultados indicam resposta acentuada de anticorpos $\lg A$, $\lg G$ I e lgG4 anti-C. albicans no lavado vaginal de mulheres sintomáticas com cultura positiva, sugerindo importante papel destes anticorpos na resposta imune local estimulada pela presença do fungo.

Dissertação de Mestrado apresentada à Universidade Federal de Uberlândia-UFU para obtenção do título de Mestre em Imunologia e Parasitologia Aplicadas. Trabalho realizado com auxílio financeiro da CAPES, CNPqe FAPEMIG. 


\section{SUMMARY}

IgA, IgE AND IgG SUbCLASSES TO Candida albicans in Serum and vaginal FLUID FROM PATIENTS WITH VULVOVAGINAL CANDIDIASIS

PURPOSE. To determine the levels of IgA, IgE, $\lg G$ and subclasses $(\lg G I, \lg G 4)$ antibodies specific to $C$. albicans in serum and vaginal washes from women with or without vulvovaginal candidiasis in order to evaluate the role of these antibodies in the immunopathogenesis of the disease.

Methods. Thirty women with clinical symptoms of vulvovaginal candidiasis ( 15 positive vaginal culture to $\mathrm{C}$. albicans, II negative culture and 4 positive culture to non-C. albicans) and 12 asymptomatic control women were selected. Serum and vaginal wash samples were obtained for the detection of anti-C. albicans antibodies by ELISA.

RESULTS. Symptomatic patients with positive culture showed significantly higher levels of specific IgA in vaginal washes and lower in serum than those with negative culture. Specific serum lgE levels were very low compared to vaginal lgE. High levels of total specific lgG were found in serum and vaginal washes in both groups, regardless the fungal presence or absence. Specific $\lg G \mid$ e lgG4 levels were significantly higher only in vaginal washes from symptomatic patients with positive culture, with a slightly higher $\lg G I / \lg G 4$ ratio, indicating that the $\lg G I$ antibody response may be predominantly involved in the fungal clearance.
CONCLUSION. Our results indicate a pronounced antibody response of $\lg A, \lg G I$ and lgG4 to $C$. albicans in vaginal washes in symptomatic patients with positive culture, suggesting a important role of these antibodies in the local immune response triggered by the presence of the fungus. [Rev Assoc Med Bras 2003; 49(4): 434-8]

KeY words: Vulvovaginal Candidiasis. Candida albicans. IgA. IgE. IgG. IgGI. IgG4. Immunopathogenesis.

\section{RefERÊNCIAS}

I. Luna MA. Candidiasis. In: Connor DH, Chandler FW, editors. Pathology of infectious diseases. Stamford, Connecticut: Appleton \& Lange; 1997. v.2, p.953-64.

2. Kirkpatrick $C$. Host factors in defense against fungal infection. Am J Med I 984; 77: I - 12.

3. Hurley R. Recurrent Candida infection. Clin Obstet Gynecol I98I; 8:209- I4.

4. Clancy R, Corrigan E, Dunkley M, Eyers F, Beagley K. Recurrent vulvovaginal candidiasisallergy or immune deficiency? Int Arch Allergy Immunol I 999; I I 8:349-50.

5. Brandtzaeg P, Farstad IN, Haraldsen G. Regional specialization in the mucosal immune system: primed cell do not always home along the same track. Immunol Today 1999; 20:267-76.

6. Moraes PSA. Estudo da associação entre candidíase vaginal de repetição e a rinite alérgica. Rev Bras Alergia Imunopatol I 995; I 8:86-90.

7. Witkin SS, Jeremias J, Ledger WJ. A localized vaginal allergic response in women with recurrent vaginitis. JAllergy Clin Immunol I 988;8 I:4 I 2-6.

8. Burges G, Holley HP Jr, Virella G. Immunoglobulin class of anti-Candida antibodies in patients with vaginal candidiasis. Diagn Immunol 1 986; 4:43-6.

9. Gough PM, Warnock DW, Richardson MD, Mansell NJ, King JM. IgA and IgG antibodies to
Candida albicans in the genital tract secretions of women with or without vaginal candidosis. Sabouraudia 1984; 22:265-7I.

10. Romero-Piffiguer MD, Vucovich PR, Riera CM. Secretory IgA and secretory component in women affected by recidivant vaginal candidiasis. Mycopathologia 1985; 91:165-70.

II. Warnock DW, Milne JD, Fielding AM. Immunoglobulin classes of human serum antibodies in vaginal candidiasis. Mycopathologia 1978; 63:1 73-5.

12. Mori JC, Pires MC, Galvão CE, Ferreira de Mello J, Golcher FM, Montealegre F. Determination of Blomia tropicalis-specific lgE and IgG subclasses in atopic dermatitis patients. Allergy 200 I; 56: 180-4.

13. SmithAM, Yamaguchi H, Platts-Mills TA, Fu SM. Prevalence of $\lg$ anti-Der $p 2$ antibodies in children from high and low antigen exposure groups: Relationship of lgGand subclass antibody responses exposure and allergic symptoms. Clin Immunol Immunopathol I998; 86: 102-9.

14. Silva DAO, Gervasio AM, Sopelete MC, Arruda-Chaves E, Arruda LK, Chapman MD, et al. A sensitive reverse ELISA for the measurement of specific IgE to Der $p$ 2, a major Dermatophagoides pteronyssinus allergen. Ann Allergy Asthma Immunol 200 I; 86:545-50.

15. Yi FC, Cheong N, Shek PCL, Wang DY, Chua $K Y$, Lee BW. Idendification of shared and unique immunoglobulin $E$ epitopes of the highly conserved tropomyosins in Blomia tropicalis and Dermatophagoides pteronyssinus. Clin Exp Allergy 2002; 32: I 203- 10.

16. Sobel JD. Candidal Vulvovaginitis. Clin Obstet Gynecol 1993; 36: 153-65.

17. Bohler K, Klade H, Poitschek C, ReinthallerA. Immunohistochemical study of in vivo and in vitro IgA coating of Candida species in vulvovaginal candidiasis. Genitourin Med 1994; 70:182-6.

Artigo recebido: 03/01/2003

Aceito para publicação: 24/04/2003 